\title{
InVestigating the LAnguage of DeCision-MAKING: The Combined Use of Discursive Practices
}

\begin{abstract}
The text draws on authentic business meetings data collected during a longitudinal study undertaken in a British Chamber of Commerce and Industry; it presents a conversation-analytical approach to the examination of decision-making. The paper adopts the format of a single-case analysis to document how speakers employed three selected discursive practices - Explanations, Accounts, and Formulations - either to launch their contributions or to maintain their influence in multi-party meetings interactions. Specifically, it reports on the phenomenon of how speakers combined these practices in the form of extended turns and how such sequential organisation of their talk facilitated the progression of the meeting. Although the practices have long been of interest to conversation analysts, the examination of their combined use and joint impact on decision-making is innovative and original to the research reported.
\end{abstract}

Key words

Accounts - Explanations - Formulations; business meetings; Conversation Analysis (CA); decision-making; discursive practices; multi-party talk

\section{Introduction}

The current contribution builds on the work of a doctoral thesis completed at the University of Birmingham (UK) in 2012 in which CA was employed as a methodology in the examination of decision-making in business meetings. In terms of published work, it offers further insights into the discursive examination of decision-making introduced in Lohrová (2014). One point of interest to have emerged from the study was the practice of participants in combining a number of specific 
discursive practices in order to communicate complex issues, ideas, and proposals. It was observed that individuals who deployed this conversational skill effectively created the opportunity to make their points and have their messages heard. The specific feature of having one's message heard constituted an important element of the decision-making talk in the meeting and consequently of the decisions made.

To set out some of the preliminaries to the analysis reported, the data extract below will be considered (the transcription conventions applied are listed at the end of the paper). In this instance, the data are drawn from the IT User Group (ITUG) that meets periodically every eight weeks; its members are representatives of all Chamber departments. The role of the group is to address and resolve IT issues as well as to facilitate the exchange of information about the Chamber's IT services between users and the IT team. The talk is centred around the raising of a specific IT issue - arrowed in Turn 50 - and the on-going discussion on how to resolve this.

\section{Data sample 1. ITUG02 Meeting: The Green Button}

ITUG02 <n Marcus>SkillsDepartment(Chair), <nLiz>SkillsDepartment(minutes), <nAlistair $>$ IT, <nAmanda $>$ International, $<$ Cohen $>$ Skills Department, $<n$ Sharin $>$ Head of $I T,<n$ Garry $>$ Business Planning, $<$ n Mike $>$ Regeneration Team, $<$ n Steve $>$ Finance, $<$ n Duncan $>$ Business Link, $<$ n Ron $>$ Events

Uhm,(1)l've been using (name of organisational CRM system), (0.8) not for a very long time now, (0.3) but a thing l've noticed, $(0.6)$ that l am getting very frustrated with, if you wanted to $(0.5)$ find say (0.6) a (name of city) Council file, (0.7) if (50:20) you type in (name of city) Council in your search, (0.3) and you pick one, (1.4) when you've picked the one you want to look at, if it's not the correct one, $=$ <n Marcus> <nAmanda> $<$ n Garry>

\section{$<$ Cohen>}

= You lose them all=

= you lose every every other one. $[<A>M h m]$ Can this be altered at all?

This is like multiple entries $(0.2)$ for the same organisation?

Yeah, we [have the same.]

[Yes, there's] there's two things here. There's- - uh $(0.3)$ it'd be [ $\langle\mathrm{C}\rangle$ (coughs)] the format of the addresshasjustbeenchanged, sothere'smore(0.4)uheasilyidentifiable(50:40)WHATDEPARTMENTS it is, (0.7) uh I think, it's been put in address line one. And the second thing is, uh $(0.4)$ rather than opening up the whole company, $(0.3)$ you see uh, $(0.3)$ when you get a listing, you see green buttons downthe lefthandside_(0.3)youjustclick on that, itopensupasmallerpanel, $(0.4)$ in which you can hopefully see whether it's the right company, [ $<C>\operatorname{Right}(\mathrm{pp})]$ if it's not, $(51: 00)$ you canclosethatdownbutyou still retainyouryourmasterlist. [ $<M>$ Yeah]So, you don'tactually havetolookatthewholecompanyand thengo backanddothesearchagain $=$ (lots of background noise from the street)

$<n$ Cohen> =Because thatalso happens, if you are not putting in the full name as well, $(0.3)$ 'cause you're not sureifthefuller,(0.5)actuallybeingenteredinto(nameoforganisationalCRMsystem). [<G>Yeah] [<S> Yeah] So, sometimes you DON'T put in the full

$<n$ Sharin $>$ The green [button should be- -]

$<n$ Cohen $>$ [The green button's] on the side? (51:20)

$<n$ Sharin> Yes

<n Marcus> Can you can you check that out, COHEN, [<C> Yeah] and give any feedback on (0.3) how that worked.(0.4) Ok. (1) Anything else? (51:25)

<n Alistair> We'vewe'vehadarequestinto(0.4)putsomemore information intothatpanelaswell,sothatwas I??/ So that's probably [/progress/]

$<$ Sharin> $[/ ? ? /](\mathrm{pp})$ 
The extract presented epitomises a problem-solving discussion, with the issue being stated, discussed, and resolved. Taking just over one minute of the meeting's time, six participants out of eleven who attended made a contribution to the talk. This is, in the context of the meeting's talk, a relatively short and unproblematic sequence. Although brief, the exchange is dynamic and discursively rich, featuring examples of latching, overlapping, and back-channel responses as the members of the team collaborate in resolving the issue.

Two turns in the transcript are substantially longer than others. Turn 50 has been pre-allocated by the Chair, who invited the team representatives to raise any issues they had. In response, Cohen took the opportunity to report a problem he had experienced with the CRM system. Turn 55 is, in contrast, self-initiated by Garry; it directly resolves the issue. Noticeably, the other speakers oriented their contributions towards these extended turns. In their immediate responses to Turn 50, they confirmed their understanding of the issue or expressed the fact that they had encountered the same problem. In Turn 56, Cohen continues to describe what he perceives as the non-functionality of the system and has, at this point, not grasped fully the solution offered to him by Garry in Turn 55. From Turn 57 onwards, the meeting's participants - including Cohen - began, however, to vocalise that they have understood Garry's explanation of the solution.

A decision was reached in Turn 60 (highlighted in grey) committing people, resources, and time to a course of action. This was issued in the form of an instruction - 'Can you can you check that out, COHEN, $[<\mathrm{C}>$ Yeah] and give any feedback on (0.3) how that worked. (0.4)'. In this case, Marcus the Chair requests Cohen to go away, check that the system functions as described by Garry, and report back with his confirmation.

Turn-taking when speakers are either granted or able to hold a larger proportion of the conversational floor has been conventionally described as 'interactional asymmetry' (Drew and Heritage 1992). Drew and Heritage (1992) maintain that interactional asymmetries are a regular feature of institutional and workplace interactions; for example, studies undertaken in the areas of classroom discourse (e.g. Sinclair and Coulthard 1975), courtroom talk (e.g. Atkinson and Drew 1979), news interviews (e.g. Heritage 1985), mediation (e.g. Greatbatch and Dingwall 1989), medical consultations (e.g. Heath 1992), or psychotherapy (e.g. Antaki et al. 2005) persuasively document this. In the meetings data analysed, interactional asymmetry took the form of some turns' being considerably longer than others. Although it may be tempting to attribute this feature to professional roles and status, i.e., the boss does all the talking, the asymmetry became more informative when subjected to a detailed analysis seeking to find out what was actually occurring. Drew and Heritage (1992: 53) summarise this necessary CA pursuit, that of not jumping too quickly to obvious conclusions regarding the reasons for the occurrence of asymmetries, in the following words:

Given the ease with which asymmetries in conduct can be interpreted in terms of exogenous variables, their analysis should properly begin by 
addressing those features of the interaction to which the participants' conduct is demonstrably oriented.

In CA terms, it is therefore appropriate to ask what occurred discursively in the extended turns observed throughout the meetings data and what impact, if any, these extended turns had on decision-making in meetings.

Below, after a brief discussion of the data upon which the present article draws, the analysis begins with an introduction to the concept of discursive practices and of how this informed the methodology adopted for the examination of decisionmaking talk.

\section{Background to the analysis}

The target organisation - a large British Chamber of Commerce and Industry - was selected to be representative of the communication undertaken within the corporate environment of the public sector. The research was intended to investigate decision-making in meetings. For that purpose access was negotiated to operational meetings: these had functional responsibility for Chamber work, were held regularly, and enabled the enactment of decision-making at a middlemanagement level.

The Chamber employed 250 members of staff organised into 11 teams, each headed by a Senior Operations Manager (SOM) who was, respectively, responsible for a specific area of work. Hierarchically, the SOMs met with the Chief Executive on a weekly basis at the Senior Management Team (SMT) meeting to review strategic performance. Weekly, they also met with their respective teams to review operational performance. SOMs had full budgetary and almost total operational autonomy over their teams and were expected to take operational decisions without recourse to the Senior Management Team.

At the time of the research (2005-2006), the Chamber was undergoing a period of major change stemming from the restructuring of the delivery of publicly funded business support services (Business Link) across the region. It entailed the centralisation of these services - then delivered sub-regionally by six Chambers of Commerce - into a single regional body, with a concomitant and significant loss of staff, financial contribution, and influence.

The data were collected over the period of one year across three different work teams: 1) the Regeneration Team (REG); 2) the International Trade Advisers' Team (ITA), and 3) the IT User Group (ITUG). Both the REG and ITA teams had a fixed membership, were responsible for the delivery of key projects, and met weekly. The ITUG had representatives drawn from all Chamber teams and met every eight weeks to discuss IT issues. Each of the three was chaired by a Senior Operations Manager (SOM). In total, sixty-seven meetings were recorded, comprising over sixty hours of spoken data of which eight hours were transcribed and subjected to analysis. 


\section{CA Methodology: Focus on discursive practices}

As a methodology, Conversation Analysis (CA) recognises talk as a naturally occurring system consisting of conversational processes and rules. These are inherently understood or are learned by speakers because they help to structure and organise talk in interaction. Founded in the 1960s and 1970s by Harvey Sacks, Emanuel Schlegloff, and Gail Jefferson, CA methods may be described as systematic and replicable, enabling researchers to undertake an in-depth analysis of localised instances of natural talk, of its turn-taking and conversational management. CA is therefore ideally suited to examining, understanding, and explaining what is occurring through talk, and to what effect.

One of the specific focuses applied by CA is the examination of discursive, or as also termed conversational, practices. Discursive practices often both characterise and form spoken interaction in specific contexts. The fact of their frequent occurrences and constrained meanings in some areas of talk yet not in others has even been proposed as providing a gateway to the interpretation of diverse discourse genres and to the related socio-cultural and professional practices (e.g. Bhatia 1993, 2004).

In business meetings, discursive practices have been described, for example, by Handford (2010) in the data collected as part of the CANBEC (Cambridge and Nottingham Business English Corpus). As Handford (2010: 66) argues, in the business-meeting genre discursive practices "signify recurrent patterns of linguistic behaviour that are decipherable in transcripts of business meetings". Handford (2010) approached the analysis from a corpus point of view, through which he identified a set of specific word clusters that were repeated across a body of meetings data. He then explained how these 'language prefabricates' become constitutive of more substantial discourse-marking and interactional practices. By illuminating how workplace goals are achieved through the use of specific lexis, Handford thus sets out a quantitative way of describing some of the "recurrent patterns of linguistic behavior" so characteristic of business meetings communication.

Studies of discursive practices may therefore originate from within different theoretical frameworks, and different methodological approaches. However, among these, CA holds a firm and respected position. CA identifies discursive practices as these emerge from within and simultaneously together with their context of use; that is, context is built through interaction and it "is both a project and product of the participants' actions" (Heritage 1997: 163). This reflexive approach to context enables an insight into the situated meaning of talk and into the specific interactional consequences enacted by the practices in conversation once their respective properties have been put into action. Heritage and Clayman (2010: 16) summarise this research pursuit in the following words: 
[C]onversation analysis involves identifying particular conversational practices and pinning down their contexts of occurrence, their meanings and consequences, and their place within larger orders of conversational organization.

Recognising a discursive practice as unique and as having specialised interactional properties requires it, though, to meet certain criteria. These have been usefully encapsulated in the following definition provided again by Heritage and Clayman (2010: 16):

To be identified as a practice, a feature of talk must (1) be recurrent, (2) be specifically positioned within a turn or a sequence (or both), and (3) have some specific interpretation, consequence or set of consequences.

Such specification implies that discursive practices may be identified as conversational units only if they typically feature in or are constitutive of a particular part of a speaker's talk. In addition, the form and interactional positioning of the practice need to also assist the speaker to meet either a desired or desirable social or professional goal.

Determining distinct discursive practices in institutional and workplace contexts demands yet another consideration. On the one hand, these contexts have been found to feature the absence of certain conversationally recurrent discursive practices and, on the other, to exhibit an overuse of a limited range of others. Drew and Heritage (1992: 22; italics in the original) attribute this specificity to three main aspects in particular:

1. Institutional interaction involves an orientation by at least one of the participants to some core goal, task or identity (or set of them) conventionally associated with the institution in question. In short, institutional talk is normally informed by goal orientations of a relatively restricted conventional form.

2. Institutional interaction may often involve special and particular constraints on what one or both of the participants will treat as allowable contributions to the business at hand.

3. Institutional talk may be associated with inferential frameworks and procedures that are particular to specific institutional contexts.

Institutional contexts therefore both require and limit the use of discursive practices to those that directly align with achieving workplace and professional goals. By implication, this results in the "reduction and respecification" (cf. Heritage 1997, 2005 ) in the range of discursive practices employed to perform "the business at hand". Hence, it is the examination of these discursive practices that provides a rich source of information on how decision-making processes are enacted through talk.

In the business meetings data analysed, the discursive practices identified as continually recurring included Explanations (E), Accounts (A), and Formulations (F). 
These were found to be prominent in constituting extended turns, used both individually and in their possible combinations (C). Examined through the lens of CA, the extended turns were subjected to an analysis in order to establish whether and how, if at all, the practices influenced decision-making as talk unfolded in the meeting.

\section{Data analysis}

In the business meetings attended and of which over 60 hours of data were recorded, extended turns presented a significant feature of the spoken interaction. In the eight hours of transcribed data that were subjected to a more detailed analysis, approximately $11 \%$ of turns represented more than $50 \%$ of the meetings' talk. Often, the percentage of turns was higher in favour of extended turns. The compelling relationship between the frequency and length of the extended turns that were produced in the meetings directed the focus of the analysis. The findings subsequently provided insight into how and why it was within these turns that decision-making was formed and was enacted discursively.

On a more pragmatic level, the rationale to base the examination of the data upon the analysis of extended turns was further guided by two strands of circumstantial evidence derived from the data collected. Firstly, the discourse leading to decisions in meetings was essentially to:

- Consider and discuss the key issues then ultimately agree on further action or make a decision;

- Discuss and plan the implementation of a decision;

- Communicate a decision already made.

Accomplishing any of these required time to build, through debate and discussion, towards a shared understanding and, at the same time, engage the team in creating, supporting, and implementing the decisions. The discourse enacting this activity tended, in consequence, to produce longer stretches of talk.

Secondly, observation of the meetings identified the perception that in addition to the recurrence of Explanations, Accounts, and Formulations in the meetings conversations, these discursive practices also clustered around decisions made in meetings (see Figure 1 for a visual representation of this feature).

The analysis applied CA to the mapping out of the discursive practices and to their coding when working with a considerable volume of transcribed data. This is demonstrated in the presentation of the findings obtained through an examination of one meeting - ITUG01 - recorded in June 2005. The meeting lasted 75 minutes 47 seconds, and was transcribed in its entirety. 


\subsection{Analysis design}

The design of the analysis required that decisions be contextualised within sizeable stretches of talk and the interactions then analysed beyond their surface level. For this purpose, a two-tier, macro-/micro-approach was developed for the textual analysis of the data. Its principles could be described as follows:

1. The transcripts were coded for time to enable the identification of extended turns;

2. Coding was developed to indicate at a macro-level the discursive practices of Explanations (E), Accounts (A), Formulations (F), and their combinations $(\mathrm{C})$ occurring in the extended turns. An additional category 'Other' (Z) identified contributions in which the practices either singularly or in combination represented less than 80 per cent of the turn;

3. Decisions were identified in the transcript;

4. The results were subsequently converted into a graphic interpretation (interactional matrices) showing the relationship among the discursive practices, the progression of the meeting, the speakership, and decisions;

5. At the micro-level, Explanations, Accounts, and Formulations were explored through a detailed textual analysis of the transcripts, and decisionmaking was analysed in relation to the use of these discursive practices in the extended singular and combination turns.

As regards the time coding of the transcripts, all turns were measured in terms of their length. Ten-second time-markers were embedded into the transcripts to enable extended turns to be identified and logged. The minimum limit for an extended turn was set at ten seconds. The ten-second criterion was, although apparently arbitrary, decided upon; the choice was made as a result of observations of the meetings. It was noted that if the speaker maintained the floor for longer than ten seconds, they were able then to continue their extended turn.

At the macro-level, the transcripts were analysed in terms both of the overall meeting dynamics, and of the individual speakers' contributions. The framework used to process and evaluate the contribution of each participant was developed as an Excel database. Once the transcripts had been exported into Excel and formatted to enable text searching, it was possible to analyse the discursive practices in detail. Subsequently, the micro-analysis deconstructed the extended turns into their constituent parts and noted the sequence in which the practices occurred in the Combination turns. In addition, each practice within the turn was subjected to a close textual analysis, describing the type of the practice, identifying the degree of its impact on the decision process, and explaining the interactive role of its constituting discourse. The results of the data analysis were summarised, and then presented in charts and graphically in interactional matrices. 


\subsection{Macro-analysis - Extended Turns}

The macro-analysis of the ITUG01 meeting examined all extended turns and decisions produced in the meeting. The principal results regarding the dynamics of the meeting are contained in ITUG01 interactional matrix in Figure 1, below. The matrix tracks the sequential organisation of speakers' contributions in the meetings, the frequent use of the discursive practices in the extended turns, and the clustering of decisions around these. The horizontal $x$ axis represents turntaking. The vertical $y$ axis notes Decisions, Explanations, Accounts, Formulations, Combinations, and the miscellaneous category 'Other' (typically performing the chairing and management function of the meeting or sustaining social interactions). All decisions made in the meeting were identified and marked with a black circle $(\bullet)$.

Figure 1. ITUG01 Interactional Matrix

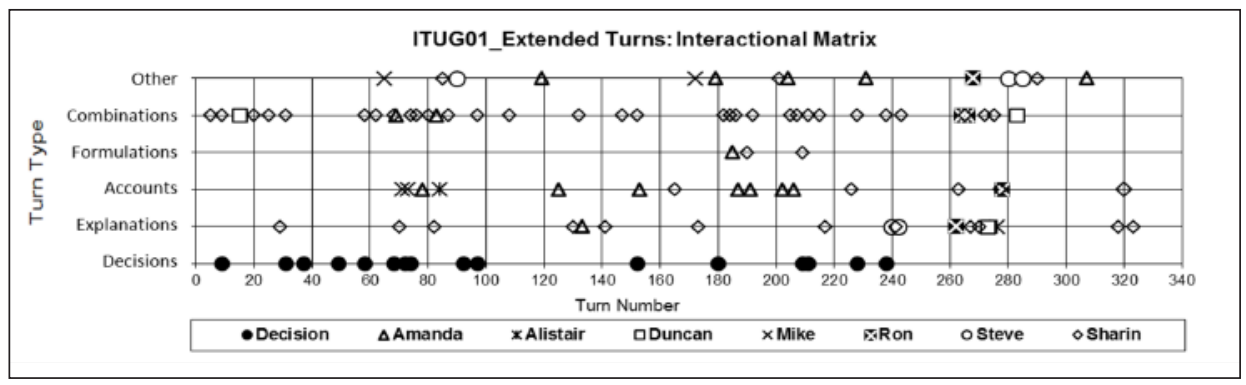

The matrix provides a visual representation of the meeting's dynamics and the discursive interactions as these unfold over time. It demonstrates the frequency of the use of the three discursive practices by meeting's participants either in singular or in combination turns, and the relationship of the practices to decisions as they occurred. The most prolific user of Combination turns was Sharin - the Chair, and Head of the IT Department. In the matrix (Figure 1), Sharin's participation is marked by a diamond $(\diamond)$.

Figure 2 provides an overview of how time was utilised in the meeting in the context of both short and extended turns. In ITUG01 (75 minutes 47 seconds), extended turns consumed in excess of 60 minutes of the meeting's time ( $3730 \mathrm{sec}-$ onds out of 4547 ), yet represented 89 out of 356 turns produced in the meeting. That is, $82 \%$ of the meeting's time was enacted in extended turns even though these constituted only $25 \%$ of all turns produced in ITUG01. This time signature further emphasises the importance of long turns in the meeting and underpins the discursive activities illustrated in the interactional matrix in Figure 1 above. 
Figure 2. ITUG01 Overview

\begin{tabular}{|l|r|}
\hline \multicolumn{2}{|c|}{ ITUG01_OVERVIEW } \\
\hline Length of the meeting in seconds & 4547 \\
\hline Number of speakers & 10 \\
\hline Total number of turns & 356 \\
\hline Number of extended turns & 89 \\
\hline Duration of Extended Turns (ETs) in seconds & 3730 \\
\hline Duration of Short Turns (STs) in seconds & 817 \\
\hline Number of decisions made & 16 \\
\hline
\end{tabular}

Figure 3 undertakes a macro-analysis of each individual's use of extended turns, the duration of the meeting's time each commanded, and the decisions they enacted.

Figure 3. ITUG01 - Extended Turns Distribution Analysis

\begin{tabular}{|c|c|c|c|c|c|c|}
\hline \multicolumn{7}{|c|}{ ITUG01_STATS (Focus on ETs) } \\
\hline Speaker & No. turns & No. ETs & $\begin{array}{c}\text { Frequency } \\
\text { of ETs } \\
\text { in } \%\end{array}$ & $\begin{array}{c}\text { ETs } \\
\text { duration (s) }\end{array}$ & $\begin{array}{c}\text { Duration of } \\
\text { ETs in } \%\end{array}$ & Decisions \\
\hline Sharin & 140 & 53 & $15 \%$ & 2995 & $66 \%$ & 13 \\
\hline Alistair & 18 & 3 & $1 \%$ & 45 & $1 \%$ & 1 \\
\hline Amanda & 90 & 17 & $5 \%$ & 350 & $8 \%$ & 0 \\
\hline Cohen & 4 & 0 & $0 \%$ & 0 & $0 \%$ & 0 \\
\hline Duncan & 16 & 2 & $1 \%$ & 40 & $1 \%$ & 1 \\
\hline $\mathrm{Liz}$ & 7 & 0 & $0 \%$ & 0 & $0 \%$ & 0 \\
\hline Mike & 25 & 4 & $1 \%$ & 80 & $2 \%$ & 1 \\
\hline Ron & 12 & 5 & $1 \%$ & 140 & $3 \%$ & 0 \\
\hline Steve & 20 & 5 & $1 \%$ & 80 & $2 \%$ & 0 \\
\hline Helena & 2 & 0 & $0 \%$ & 0 & $0 \%$ & 0 \\
\hline All & 22 & 0 & $0 \%$ & 0 & $0 \%$ & 0 \\
\hline TOTAL & 356 & 89 & $25 \%$ & 3730 & $82 \%$ & 16 \\
\hline
\end{tabular}

There was a distribution of turn-taking, the use of extended turns, and decisionmaking across the meeting's participants. However, the dominance of Sharin in terms of his overall production of extended turns and decisions is immediately obvious. In the analysis, Amanda was the second most prolific user of extended turns; however, a subsequent micro-analysis of her discourse revealed that she was predominantly accounting for the actions of her team yet not actually making any real contribution to the decision-making of the meeting. This reinforces the necessity of undertaking a finer-grained analysis of the discourse occurring.

Returning to the share of Sharin's contribution: it is apparent especially when his extended turns are again re-calculated in terms of duration and the decisions 
made. Figure 4 summarises Sharin's talk.

Figure 4. ITUG01 - Sharin's Talk

\begin{tabular}{|l|c|}
\hline Sharin's talk in the meeting & $\%$ \\
\hline Percentage of all turns in the meeting & $39 \%$ \\
\hline Percentage of ETs in the meeting & $60 \%$ \\
\hline Percentage of all Sharin's turns that were ETs & $38 \%$ \\
\hline Duration of Sharin's ETs as a proportion of all meeting's time & $66 \%$ \\
\hline Duration of Sharin's ETs as a proportion of all ETs & $80 \%$ \\
\hline Decisions & $81 \%$ \\
\hline
\end{tabular}

Sharin effectively commanded nearly two-thirds of the meeting's time (66\%). In reality, this figure was even slightly higher, as he also contributed in the short turns, which in the ITUG01 meeting represented approximately $18 \%$ of the total meeting's time. Significantly, he made 13 out of 16 decisions $(81 \%)$ and there was clearly a relationship between extended turns and decision-making.

Figure 5 (Decisions Overview) expands on the information presented in the ITUG01 interactional matrix (Figure 1) regarding the decisions enacted in the meeting. In particular, it provides additional textual information on the decisions and the language form in which the decisions were communicated.

Figure 5. ITUG01 - Decisions Overview

\begin{tabular}{|c|c|c|c|c|}
\hline \multicolumn{5}{|c|}{ ITUG01: Decisions Overview } \\
\hline No. & Turn & Speaker & Text & D. form \\
\hline 1 & 9 & Sharin & $\begin{array}{l}\text { So, if the group is happy with this, } \\
{[<\mathrm{L}>\text { Yeah }](0.2) \text { we'll }(0.2) \text { put an area }} \\
\text { for the I.T. user group, where we can put } \\
\text { our documents in there, so, }(0.2) \text { anybody } \\
\text { in the company can see it. }(03: 00) \text { And } \\
\text { uh we'll put the terms of reference there } \\
\text { as well. So, we'll get on with it, }(0.3) \text { and } \\
\text { and do that. (8) }\end{array}$ & $\begin{array}{l}\text { action with } \\
\text { a condition }\end{array}$ \\
\hline 2 & 31 & Sharin & So, we'll do that, nearer the time. & action \\
\hline 3 & 37 & Duncan & $=$ Oh I I've got no problem with it & action \\
\hline 4 & 49 & Mike & Oh yeah, [I'll do it] & action \\
\hline 5 & 58 & Sharin & $\begin{array}{l}(0.8) \text { I WILL }(14: 40)(0.3) \text { perhaps send } \\
\text { an email }(0.2) \text { next week, to tell the whole } \\
\text { organisation, who the two members are, } \\
\text { and what they will be working on. ... So, } \\
\text { I'll do that }(0.2) \text { next week }(15: 00)\end{array}$ & action \\
\hline
\end{tabular}




\begin{tabular}{|c|c|c|c|c|}
\hline \multicolumn{5}{|c|}{ ITUG01: Decisions Overview } \\
\hline No. & Turn & Speaker & Text & D. form \\
\hline 6 & 68 & Sharin & $\begin{array}{l}\text { the Blackberry devices will be }(0.4) \text { uh } \\
\text { I HOPE you guys have, }(18: 00) \text { I don't } \\
\text { know, have had some communication } \\
\text { from your managers to say }(0.3) \text {, they'll } \\
\text { be rolled out, }(0.2) \text { uh }(0.2)\end{array}$ & action \\
\hline 7 & 72 & Alistair & $\begin{array}{l}\text { You don't need to phone us, }(0.3) \text { you can } \\
\text { do it on the Intranet, }(0.2)\end{array}$ & instruction \\
\hline 8 & 74 & Sharin & Yes. Yes, it is necessary. & instruction \\
\hline 9 & 92 & Sharin & $\begin{array}{l}\text { Not a problem, }(0.2) \text { we'll }(0.2) \text { we'll } \\
\text { send an email. }\end{array}$ & action \\
\hline 10 & 97 & Sharin & $\begin{array}{l}\text { So, what we'll do, }(0.2) \text { will send an } \\
\text { EMAIL, to REMIND people to LOOK at } \\
\text { THAT document, basically. }(0.2) \ldots(0.4) \\
\text { Uh so I'll I'll }(0.4) \text { I'll send an email out, } \\
(0.2) \text { to remind people }(10)(29: 40) \\
\end{array}$ & action \\
\hline 11 & 152 & Sharin & $\begin{array}{l}\text { No, uh }(0.7) \text { seriously, }(0.3) \text { if it is if it is } \\
\text { a business requirement, then we will have } \\
\text { to accommodate it somehow, we will look } \\
\text { into it, }[<\mathrm{A}>\mathrm{Mhm}] \text { with you, }(0.2)\end{array}$ & $\begin{array}{l}\text { action with } \\
\text { a condition }\end{array}$ \\
\hline 12 & 180 & Sharin & $\begin{array}{l}\text { Uh }(0.3) \text { the: short answer is, }(0.4) \text { the } \\
\text { OWNER of the equipment, }(0.2) \text { should } \\
\text { support THAT equipment. If we own it, } \\
(0.2) \text { we will support it. }\end{array}$ & action \\
\hline 13 & 209 & Sharin & $\begin{array}{l}\text { It it it depends on what you want. } \\
\text { BUT (f), if it's an issue, talk to to I.T. } \\
\text { DIRECTLY, }(0.2)[<\mathrm{A}>\mathrm{Mhm} \text { ] talk to ME } \\
\text { directly, and say, we want to do this on } \\
\text { the portal. THEN I can say to you, YES, } \\
(0.5) \text { we can }(0.2) \text { do this, and I'll bring in } \\
\text { Marketing with that. If it's an ISSUE.= }\end{array}$ & instruction \\
\hline 14 & 211 & Sharin & $\begin{array}{l}\text { You talk to I.T. in the first instance, } \\
{[<\mathrm{C}>\mathrm{Mhm}] \text { stick it on the on the Support }} \\
\text { Desk. }[<\mathrm{C}>\mathrm{Mhm} \text {, yeah }]\end{array}$ & instruction \\
\hline 15 & 228 & Sharin & $\begin{array}{l}\text { And if that is- - If I see that, and and I'll } \\
\text { run it past to you, and if you think, yeah, } \\
\text { that's useful, then (0.2) I'll publish it. Uh } \\
(0.2) \text { I'll TRY and DO that. [ }<\mathrm{A}>\mathrm{Ok}]\end{array}$ & $\begin{array}{l}\text { action with } \\
\text { a condition }\end{array}$ \\
\hline 16 & 238 & Sharin & $\begin{array}{l}\text { But I'll I'll put something in place, } \\
\text { and and hopefully that will help. (0.5) } \\
\text { Hopefully, that will help. }\end{array}$ & action \\
\hline
\end{tabular}

In total, sixteen decisions were enacted in the meeting. All of these were operational, directly addressing or resolving the individual agenda items. Five of the 
decisions (Decisions 3, 4, 7, 9, and 12) occurred in short turns. The remaining eleven decisions were made as part of extended turns. Interestingly, all of these eleven decisions were made or formulated by Sharin. The data further confirmed that, even for decisions produced in short turns, the rationale and the decision paths were set out by the extended turns either directly preceding the short decision-making turn or were found in its vicinity.

Focusing more closely on the distribution in the use of discursive practices employed by the individual speakers again reinforces Sharin's dominance in the meeting. A summary of discursive practices employed in the extended turns is provided in Figure 6 below:

Figure 6. ITUG01 - Overview of discursive practices employed in the Extended Turns

\begin{tabular}{|c|c|c|c|c|c|c|c|c|c|c|c|c|}
\hline \multicolumn{13}{|c|}{ ITUG01_STATS (Overview of discursive practices employed in ETs) } \\
\hline \multirow{2}{*}{$\begin{array}{c}\text { Use of } \\
\text { discursive } \\
\text { practices in } \\
\text { ETs }\end{array}$} & \multirow{2}{*}{$\begin{array}{l}\text { No. of occu- } \\
\text { rrencies in } \\
\text { the meeting }\end{array}$} & \multirow{2}{*}{$\begin{array}{l}\text { Total length } \\
\text { (cummulative } \\
\text { in seconds) }\end{array}$} & \multirow{2}{*}{$\begin{array}{c}\text { No. of } \\
\text { Associated } \\
\text { Decisions }\end{array}$} & \multicolumn{9}{|c|}{$\begin{array}{c}\text { Use of the practice by individual } \\
\text { speakers }\end{array}$} \\
\hline & & & & 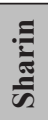 & 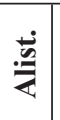 & $\underset{\dot{E}}{\stackrel{\Xi}{\Xi}}$ & 节 & 导 & $\stackrel{\mathbf{N}}{\unlhd}$ & $\stackrel{0}{i=}$ & $\tilde{\tilde{\theta}}$ & 苟 \\
\hline Explanations & 18 & 460 & 0 & 12 & 1 & 1 & 0 & 1 & 0 & 0 & 1 & 2 \\
\hline Accounts & 17 & 375 & 0 & 5 & 1 & 8 & 0 & 0 & 0 & 2 & 1 & 0 \\
\hline Formulations & 3 & 35 & 1 & 2 & 0 & 1 & 0 & 0 & 0 & 0 & 0 & 0 \\
\hline Other & 15 & 515 & 1 & 4 & 0 & 5 & 0 & 0 & 0 & 2 & 1 & 3 \\
\hline $\begin{array}{l}\text { Combination } \\
\text { turns } \\
\text { (consisting of } \\
\mathrm{E}, \mathrm{A} \text {, and } \mathrm{F} \text { ) }\end{array}$ & 36 & 2345 & 9 & 30 & 0 & 2 & 0 & 2 & 0 & 0 & 2 & 0 \\
\hline
\end{tabular}

Sharin produced the majority of Combination turns (30 out of 36). Interestingly, it was observed that during the meeting he always took the opportunity to have at least one extended turn with every agenda topic. When this is aligned with the report's finding that Sharin made nine of the meeting's decisions in extended Combination turns, there is clearly an interrelation between the use of the three discursive practices and decision-making. It may be argued that extended Combination turns thus facilitated the progression of the individual agenda items and provided the bases on which subsequent decisions were reached.

Overall, the macro-analysis of the ITUG01 mapped the contributions of the individual speakers, their continual use of Explanations, Accounts, and Formulations, their share of the meeting's time, and decisions made. In the data, the macroanalysis established a consistent use of the three discursive practices employed in combination in extended turns, and indicated the emergence of repeated sequences of the practices in these turns. This patterning of the practices and, in particular, their seemingly naturally-occurring positioning invited further research enquiry. 


\subsection{Micro-analysis - use of discursive practices}

The micro-analysis moved the focus of the investigation to a textual examination of the Combination turns identified in the ITUG01 meeting and deconstructed these into their constituent parts. It analysed Explanations, Accounts, and Formulations for their sequential organisation in the extended turns and for the impact they had on decision-making in the meeting.

Discursively, the unique roles of the three practices may briefly be described as follows. Explanations fulfilled the aspects of reporting and sharing factual information, building organisational understanding, and contributing to the knowledge pool of the team. Explanations also provided reference points against which prospective action could be evaluated. Accounts were typically employed to bridge the gap between actions and expectations (Scott and Lyman 1968). Frequently, they were problem-led and were produced either in response to a failure or in anticipation of one. Accounts consisted of opinions or interpreted experiences and provided a view based on these, i.e., they may or may not inherently be correct. Formulations were used to accomplish the "summarising, glossing, or developing the gist" of the previous talk (Heritage 1985). They were employed to signpost the progression of a conversation, summarising the speakers' understanding up to a specific point in time, or projecting a new meaning implied from the preceding discussion. Formulations featured the "preservation, deletion, and transformation" of the previous talk, which rendered them highly implicative for the subsequent talk or prospective decisions (Heritage and Watson 1979).

In the data, the textual boundaries of the three discursive practices were determined on the bases of their original definitions as formulated in the CA literature, i.e., Formulations by Heritage and Watson (1979) and Accounts by Scott and Lyman (1968). Traditionally within CA, Explanations have not received exclusive attention; rather, they have been amalgamated with Accounts. The research reported has taken the decision to differentiate between the two practices as it is argued that they performed related yet substantially diverse functions in the decision-making process. A more detailed use and typology of these practices may be reviewed in Lohrová (2012).

To illustrate the complexity, fluidity, and sequential ordering of the practices employed, Figure 7 (below) presents a snapshot of the micro-analysis of the ITUG01 meeting Combination turn T265C. The turn was of considerable length (2min $6 \mathrm{sec})$. It was therefore interesting to examine how the practices behaved within such an extended contribution. The chart deconstructs the turn into its constituent parts and subjects each individual practice to a textual analysis and considers the impact on the turn as a whole and on decision-making in particular.

The turn was constructed by Sharin and conveyed his expert opinion, given to the team in response to feedback on a new project - the Document Management System (DMS), a project of strategic value to the organisation. The successful implementation of the new system required the optimum choice of technical 
Figure 7. Meeting ITUG01_T265C - Textual analysis

\begin{tabular}{|c|c|c|c|c|}
\hline \multicolumn{5}{|c|}{ MICRO_ITUG01_T265C - Part 1/2 } \\
\hline PR. & \begin{tabular}{|l} 
Impact \\
on DM
\end{tabular} & Function & $\begin{array}{l}\text { Notes on the } \\
\text { impact }\end{array}$ & Original text \\
\hline E1 & NO & $\begin{array}{l}\text { Acknowledging } \\
\text { the existence } \\
\text { of a technichal } \\
\text { solution, } \\
\text { explaining that } \\
\text { a technical } \\
\text { solution does not } \\
\text { stand alone, and } \\
\text { asserting that the } \\
\text { organisation now } \\
\text { needs to define } \\
\text { its document } \\
\text { management } \\
\text { requirements in } \\
\text { greater detail in } \\
\text { order to select the } \\
\text { specific technical } \\
\text { solution that will } \\
\text { meet these. }\end{array}$ & $\begin{array}{l}\text { Challenging } \\
\text { people to think } \\
\text { more widely, use } \\
\text { of a formulaic } \\
\text { expression to } \\
\text { emphasise the } \\
\text { key message }\end{array}$ & $\begin{array}{l}\text { Uh (0.3) (64:00) TECHNICALLY, } \\
\text { technically, the the technology is - - } \\
\text { has advanced SO MUCH, in terms } \\
\text { of document management, (0.3) SO } \\
\text { MUCH, that (0.2) if you if you GO for } \\
\text { for a DEMO, and HAVE a LOOK at } \\
\text { systems, you think, WHOA! You know, } \\
\text { this will do everything I want it to do. } \\
\text { Technical, so technical solutions, we we } \\
\text { are spoilt for choice. There are so many } \\
\text { choices out there, that we could that we } \\
\text { could look into, and implement in place. } \\
(64: 20) \text { And as I said, (0.2), I think } \\
\text { I mentioned it earlier, it would be a piece } \\
\text { of cake, from the I.T. perspective, to just } \\
\text { grab a system, (0.2) get a server, get tons } \\
\text { of disk space, (0.2) and say to people, } \\
\text { scan and (0.2) store your data, whatever. } \\
\text { [<Al> Mhm] That's that's the EASY bit. }\end{array}$ \\
\hline A1 & NO & $\begin{array}{l}\text { Bridging the } \\
\text { expectations of } \\
\text { the group with } \\
\text { the reality of } \\
\text { how technical } \\
\text { solutions work } \\
\text { and advocating } \\
\text { the decision on } \\
\text { the new system is } \\
\text { deferred. }\end{array}$ & \begin{tabular}{|l|} 
Introducing \\
another level \\
of complexity, \\
inviting \\
involvement from \\
the users; using \\
language to paint \\
the complexity \\
of a solution and \\
that it will require \\
a great deal of \\
effort and buy-in \\
if it is to succeed
\end{tabular} & $\begin{array}{l}\text { The the more CHALLENGING bit IS, } \\
(0.2) \text { to understand EXACTLY how } \\
\text { you want to use it, and how we can } \\
\text { make it EASY for you to use, in terms } \\
\text { of }(0.2) \text { STORING your data, }(64: 40) \\
\text { INDEXING them correctly, 'cause }(0.2) \\
\text { you will have thousands and thousands of } \\
\text { documents to store in there. [ }<\mathrm{R}>\mathrm{Mhm}] \\
\text { Because you don't want to be spending } \\
\text { time THEN (f), when it comes to the } \\
\text { CRUNCH, [ }<\mathrm{R}>\text { Yeah] and you want to } \\
\text { to to LOOK at the client's file, spend two } \\
\text { hours searching for it, because then, we } \\
\text { haven't achieved much. }\end{array}$ \\
\hline F1 & NO & $\begin{array}{l}\text { Formulating } \\
\text { the bottom line, } \\
\text { summarising the } \\
\text { preferred direction }\end{array}$ & $\begin{array}{l}\text { Putting forward } \\
\text { a clear view } \\
\text { of the matter } \\
\text { discussed }\end{array}$ & $\begin{array}{l}\text { And that's the challenge, we need to } \\
\text { get a system in place, that }(0.2) \text { we're } \\
\text { ABSOLUTELY CLEAR about, WHAT } \\
\text { (65:00) requirements is it going to } \\
\text { address, }(0.4) \text { and the requirements } \\
\text { definition, that is where we are } \\
\text { struggling as a group, and and the } \\
\text { document management group. }\end{array}$ \\
\hline
\end{tabular}




\begin{tabular}{|c|c|c|c|c|}
\hline \multicolumn{5}{|c|}{ MICRO_ITUG01_T265C - Part 2/2 } \\
\hline PR. & \begin{tabular}{|l|} 
Impact \\
on DM
\end{tabular} & Function & $\begin{array}{l}\text { Notes on the } \\
\text { impact }\end{array}$ & Original text \\
\hline A2 & NO & $\begin{array}{l}\text { Bridging } \\
\text { understanding } \\
\text { across the } \\
\text { organisation, } \\
\text { using language } \\
\text { to communicate } \\
\text { arguments } \\
\text { generating trust. }\end{array}$ & $\begin{array}{l}\text { Assessing } \\
\text { progress, } \\
\text { comparing } \\
\text { between now } \\
\text { and in the future, } \\
\text { engaging the } \\
\text { group, facilitating } \\
\text { the 'talking } \\
\text { through' change }\end{array}$ & $\begin{array}{l}\text { Uh (0.4) but we're MAKING some } \\
\text { progress, and and we're CONFIDENT, } \\
\text { you know, if we get the BACKING of } \\
\text { the executive board, in terms of }(0.2) \\
\text { spending MONEY on this system, } \\
\text { uh }(0.2) \text { then, we will have a system } \\
\text { in place, which will ( } 0.8) \text { absolutely } \\
(65: 20)(0.2) \text { make it easier for people, } \\
(0.2) \text { DEFINITELY, it will, ( } 0.2) \text { it will, } \\
\text { NO DOUBT, be an improvement to } \\
\text { the current system, because the current } \\
\text { system is just chaos. (0.2) [<Al> Mhm] } \\
\text { So, any system will be better. But we } \\
\text { REALLY want to get it ABSOLUTELY } \\
\text { right. So, (0.4) in in a year's time, we } \\
\text { could (0.2) SCALE that up, and expand } \\
\text { on the usage, without having to say, oh, } \\
(0.3) \text { the system's no good, we can't } \\
\text { do any more, the Chamber has to go } \\
\text { somewhere else. }\end{array}$ \\
\hline F2 & NO & $\begin{array}{l}\text { Repeating the } \\
\text { summary of the } \\
\text { preferred direction }\end{array}$ & $\begin{array}{l}\text { Being explicit in } \\
\text { communicating } \\
\text { the key message. }\end{array}$ & $\begin{array}{l}\text { And that's the }(65: 40) \text { challenge } \\
\text { now. It's getting something that we } \\
\text { could BUILD upon, and two three } \\
\text { four five years' time, we'd we'd be } \\
\text { ABSOLUTELY }(0.6) \text { dependent on } \\
\text { that system, }(0.5) \text { you're with me? }(0.2) \\
\text { And that's where we're now. }\end{array}$ \\
\hline F3 & NO & $\begin{array}{l}\text { Drawing an } \\
\text { implication, } \\
\text { linking back to the } \\
\text { question, closing } \\
\text { the agenda point }\end{array}$ & $\begin{array}{l}\text { Linking back to } \\
\text { close a query }\end{array}$ & $\begin{array}{l}\text { So, }(0.2) \text { THAT feedback, I guess, } \\
\text { is what what is to be expected, } \\
{[<\mathrm{R}>\mathrm{Mhm}] \text { at this stage, unless we }} \\
\text { feed more to the team to say, ok, } \\
\text { HERE'S what we plan to do, }(66: 00) \\
\text { what do you THINK. Uh }(0.4) \text { but } \\
\text { we're not at that stage yet. So we'll } \\
\text { uh- - = }\end{array}$ \\
\hline
\end{tabular}

solution, informed input on the needs from all of the teams, and its quick and effective adoption by the users.

The turn employed all of the three practices, especially the initial ExplanationAccount-Formulation sequence, which built up a clear view of the issues at hand 
and stimulated further critical thinking and debate. Through the opening Explanation (E1), Sharin started to assemble a pool of factual evidence and shared knowledge regarding the DMS. The Account (A1) subsequently adopted a specific perspective towards some of the technicalities of the proposed solution. It presented the challenge posed in selecting a new system and linked it to current business processes. By articulating both the opportunities and the trade-offs of the new solution, it effectively moderated users' expectations. The Formulation (F1) completed the sequence; it invited a specific action and warned against the dangers of making a potentially wrong decision.

Although no formal decision was made regarding the implementation of the system - in pragmatic terms, no decision could be expected at this point - the turn was constructed in such a way that it created conditions for decisions to be made in the future. In the turn, Sharin furnished a framework and context within which to evaluate new information and proposals. He thus equipped the group with the understanding of what it needed to be doing and kept attention focused on the priorities of the group.

Figure 8 below illustrates graphically the decomposition of the Combination turn $\mathrm{T} 265 \mathrm{C}$ and the patterning of the discursive practices as Sharin's turn unfolded:

Figure 8. Micro-Analysis - ITUG01_T265C_Sharin

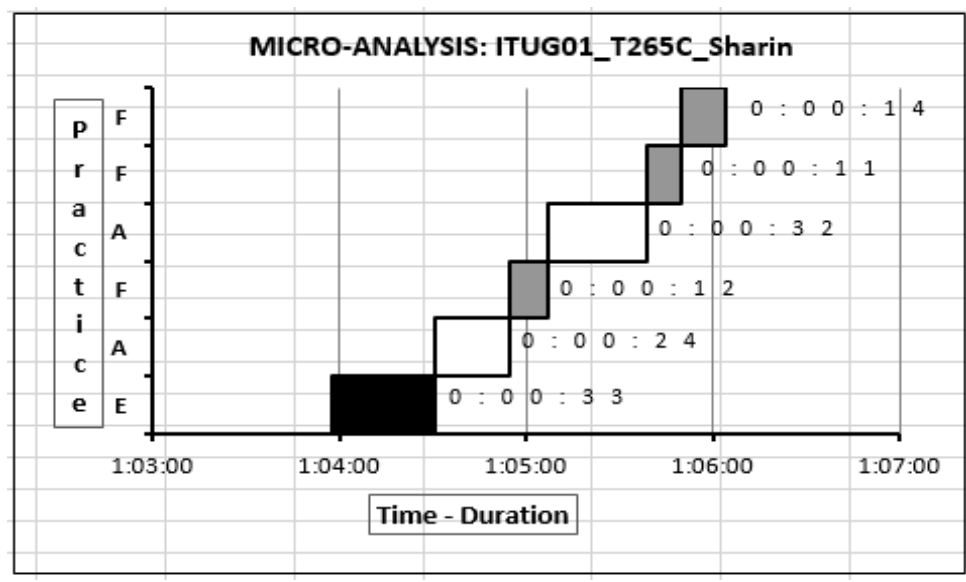

In Combination turns the patterning of the practices may be described as 'chaining'. Discursively, the chaining was observed to occur when speakers were able to draw on the individual properties of the discursive practices such that they exploited these to contribute to the purpose of the meeting or to a specific agenda point. In the instance of T265C, Sharin grounded his turn in the properties of factual reporting of an Explanation (E1). Through the Account (A1), he moderated meeting participants' expectations as he acknowledged the challenges faced by the organisation in their selecting of the appropriate DMS. By following with a Formulation (F1), Sharin preserved the essence of the critical need to have 
a new system yet also to make the right choices, and thus shifted the subsequent debate from hypothesising about a possible adoption of a new system to actually perceiving this as a favourable course of action. The ensuing sequence of $\mathrm{A} 2 \mathrm{~F} 2 \mathrm{~F} 3$ was structured to furnish confidence in the strategic planning and decision-making of the executive board (A2 justification), to reinforce the position of the organisation at this point (F2 self-formulation), and to articulate the implications for the group to feed back effectively to their respective teams (F3 appeal for action).

Hence, in Combination turns, each of the three discursive practices contributed to working in unison, using their unique properties to prevent interruption or challenge in order incrementally to progress talk and at times to advance it to where decisions could be reached. A further finding was that specific patterns of the discursive practices began to emerge in the data. As advocated in Section Three of the present article, in order to recognise, describe, and interpret the unique qualities of specific discursive practices and their consequences, it is important to establish their recurrent use and specific positioning within a turn or a sequence of talk. In the meetings data, it was the extended Combination turns that provided the insight into the role of patterning of the three practices and their combined impact on decision-making. To illustrate this finding, Figure 9 (below) extracts the thirty Combination turns produced by Sharin in ITUG01 and lists the sequences of Explanations, Accounts, and Formulations employed in these. In the chart, all Combination turns in which decisions were made have been highlighted in grey.

Figure 9. ITUG01 Sharin - Combination Turns Sequencing

\begin{tabular}{|c|c|c|c|c|c|}
\hline \multicolumn{6}{|c|}{ ITUG01 Sharin - Combination Turns Sequencing } \\
\hline Turn & Length (S) & Sequence & Turn & Length (S) & Sequence \\
\hline 5 & 40 & $\mathrm{EF}$ & 147 & 10 & FA \\
\hline 9 & 220 & AFAFEAEFAEAFE & 152 & 40 & FE \\
\hline 20 & 30 & $\mathrm{AF}$ & 182 & 45 & EA \\
\hline 25 & 45 & FEFAE & 184 & 35 & EFAF \\
\hline 31 & 75 & EAEAFA & 186 & 45 & ZAF \\
\hline 58 & 200 & EFAZAEEEFEZFAF & 192 & 20 & EFEF \\
\hline 62 & 15 & EF & 205 & 30 & $\mathrm{AF}$ \\
\hline 68 & 225 & AEFEAEF & 207 & 80 & EAFAF \\
\hline 74 & 90 & AFAE & 211 & 30 & $\mathrm{AF}$ \\
\hline 76 & 30 & EFA & 215 & 100 & AEAEEF \\
\hline 80 & 80 & $\mathrm{AF}$ & 238 & 30 & $\mathrm{AF}$ \\
\hline 87 & 130 & EAEFFAFAFAF & 243 & 60 & EF \\
\hline 97 & 50 & EFAZ & 265 & 125 & EAFAFFF \\
\hline 108 & 180 & EFEF & 272 & 55 & EZEF \\
\hline 132 & 25 & EF & 275 & 25 & $\mathrm{AF}$ \\
\hline
\end{tabular}


In the meetings data, the analysis of the patterning and of the sequential organisation of the three discursive practices therefore assisted in the understanding of how some speakers were able to maintain the conversational floor without being interrupted or challenged. For example, the initial position of Explanations in the EA or EF sequences - fifty per cent of Sharin's extended turns opened with an EA or EF combination - provided a factual base from which to develop an argument based on a logic chain. Explanations positioned at the beginning of extended Combination turns allowed the speaker the time and space to establish the credibility of the debate and subsequently to develop and communicate complex ideas. As has been demonstrated in Sharin's case, contributions opening with Explanations granted him the status of 'an expert speaker', as a result of which he was accorded the opportunity to extend his turn, deliver further information, or make a decision.

Having gained the conversational floor, it was still necessary for Sharin to continue the turn towards a specific conclusion. He used Accounts to facilitate the bridging of the group's expectations and to align them with the vision of the organisations. The practice was used sparingly, only as required, and distributed across the turn. There was a high frequency of Formulations as each point was reinforced before the speaker progressed to the next part of the turn. Almost all turns closed with a Formulation as a conclusion was reached or a decision proposed.

In summary, the micro-analysis provided the necessary detail as to how the three practices worked in harness to progress talk to decisions. It is important to emphasise that the general properties of the three discursive practices did not automatically grant the speaker the floor, nor did they guarantee the progression either of the meeting or of the related decision-making. As the micro-analysis demonstrated, it was through the situated use and sequential ordering of the practices that some speakers were able to capitalise on the unique properties of the three practices such that they combined them effectively. When each of the practices was used individually by the speakers, they had the potential either to facilitate or to obstruct the flow of the meeting's interaction and the underlying decisionmaking. For example, Amanda exhibited a propensity towards the use of Accounts. She was the second most prolific speaker: launching 17 extended turns, she neither made nor formulated any decisions in the meeting. She continually used Accounts to present a personalised perspective of issues at hand, yet failed then to progress the discussion beyond a mere description. The combined use and specific patterning of the three practices enabled speakers not only to extend their turn, but also to create an impact on the progression of the meeting.

The dominance of Sharin discursively throughout the meeting both in terms of his share of meeting turns and in the enacting of decisions is perhaps not surprising. Sharin performed a dual role within the meeting: that of Chair and of being the Senior Operations Manager in charge of IT. Both roles provided him with a large degree of authority, access to high-level information on the organisation, and the ability and requirement of his position(s) to make decisions. The question thus arises as to whether it is status and power which enabled him to dominate the meeting. 
Having power and authority creates the assumption from meeting's participants that the speaker will make decisions and manage meetings effectively. This thus accords a certain level of latitude to how speakers may conduct themselves. However, the analysis of the actual discourse demonstrated that at face value this assumption may be incorrect or stereotypical; in Sharin's case it was the deployment and continued use of the three discursive practices which enacted the decision process. This again reflects the value of CA given that it sets out to describe what is actually unfolding in talk rather than making assumptions of what might be expected to happen, i.e., the use of status and power.

\section{Conclusion}

The paper aimed to illustrate the powerful role of a sequential analysis in obtaining an in-depth insight into the discursive process of decision-making in meetings. Specifically, the focus was directed onto the investigation of three discursive practices - Explanations, Accounts, and Formulations - observed in the utterances of some speakers as combining recurrently with the effect of creating and maintaining extended turns. Being able to draw on the unique individual properties of these practices, and to chain them effectively, increased the opportunities for the speakers either to influence or to drive the decision-making process. This has been demonstrated through examples of authentic data: The Green Button and ITUG01 single-case analysis.

Importantly for the analysis, the exquisite characteristics of Explanations, Accounts, and Formulations lay in their appearing entirely unprepossessing and commonplace, rather than in their being extraordinary. The research confirmed that the practices were continually present in the meetings data - to the point where many speakers were demonstrating unconscious competence in their use. That is to say the individuals' use of the practices had become second nature to them. These speakers exploited the properties of the practices more successfully than did others, and some were also more skilful in combining their overall impact on the talk at hand. The practices formed part of their 'competency portfolio' assisting them to perform their respective professional roles.

Exploration of the combined effect of Explanations, Accounts, and Formulations in the extended turns of meetings' talk is, to the best of my knowledge, novel to the research reported. Somewhat heuristic were also the tools of interactional matrices and the visual deconstruction of the extended turns into their individual practices. Although primarily facilitative of the textual analysis of the transcripts and of the actual discursive practices occurring, these tools advanced the application of CA by developing an insight into the fluidity and dynamics of the decision-making process in meetings. The analysis enabled the processing of a relatively large volume of transcripts, as well as the examination of the sequential nature of the practices as these were employed in talk. It achieved this by targeting extended turns, as opposed to taking the traditionally narrow focus 
on conversational data. At the macro-level, the examination of the meetings' talk highlighted the reduction in the use of discursive practices across a series of institutional meetings as the participants attempted to behave professionally and to remain relevant to the agenda point at hand. Further, the analysis indicated the interconnection between the three discursive practices and decision-making. The micro-analysis subsequently identified a set of distinctive patterns in which the practices occurred in the extended Combination turns; the impact of the patterns and the complementary role of Explanations, Accounts, and Formulations within these were explored.

The practical application of the findings may therefore be assumed as being essentially twofold. One strand leads back to the environment of business organisations where, in the spirit of "partnership research", the findings may be contested, re-visited, and further honed in the context of authentic business interactions. Such an initiative will help to raise the profile and significance of talk as constituting an integral part of organisational models and perhaps be deserving of greater consideration in this context in the future. Collaboration with partnership organisations will also nurture what may later become the second, the applied, use of the CA insights obtained: to interpret and describe the communicative behaviours associated with the act of decision-making in such a way that the research findings may inform communication teaching and training.

\section{Note}

1 The term "partnership research" has been explained and advocated, for example, by BargielaChiappini and Nickerson $(2001,2002)$. Also, Sarangi and Roberts (1999: 2) evoke a similar notion in their argument for grounding the workplace communication research in "ethics of practical relevance".

\section{Transcription conventions}

Adapted from, although not identical with, standard CA conventions developed by Gail Jefferson (see Hutchby and Wooffitt 1998: vi-vii).

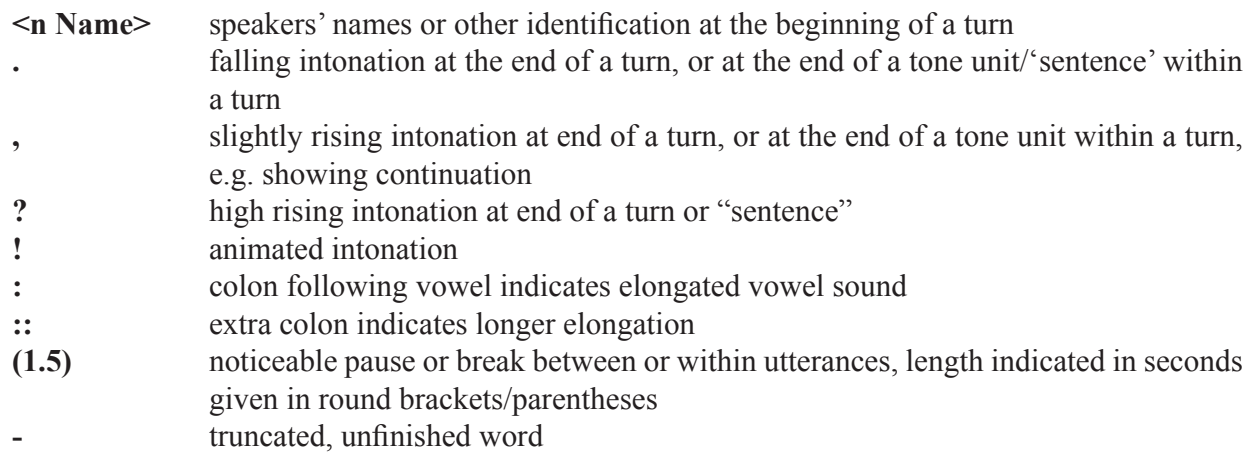




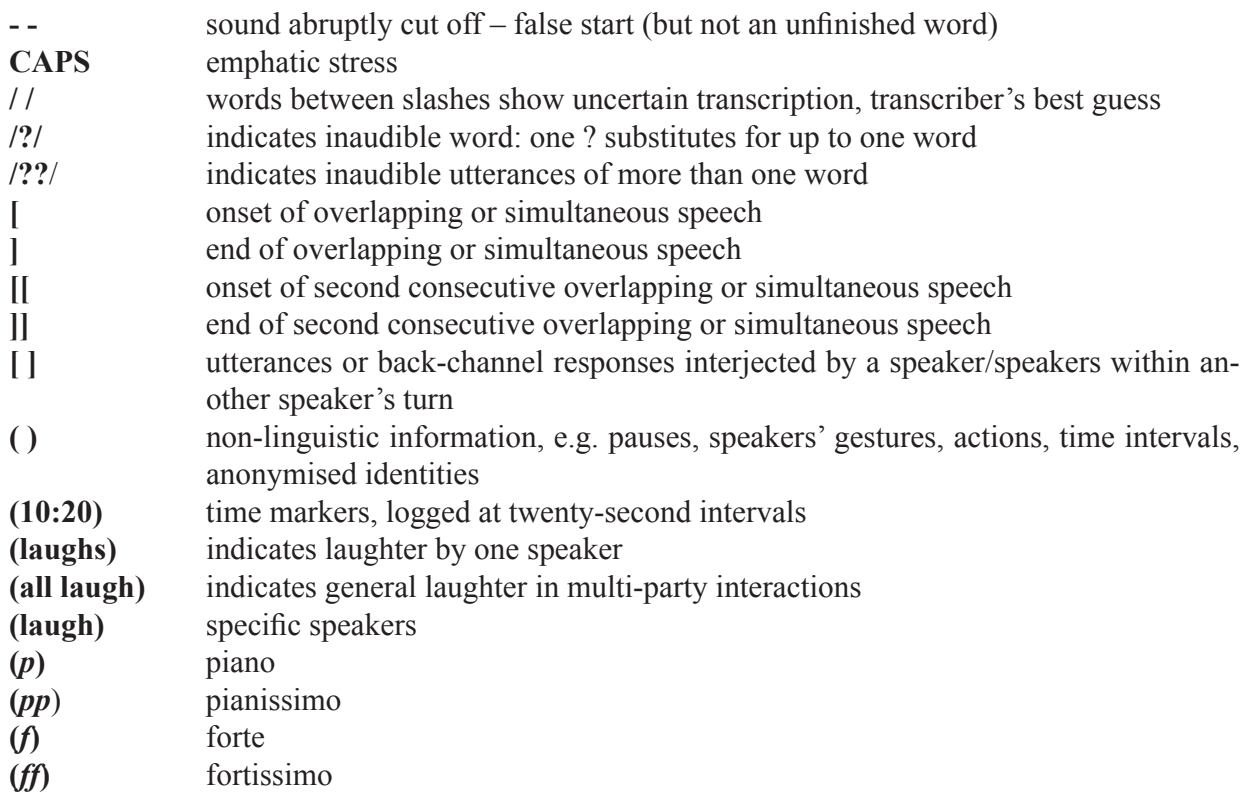

Use of standard contractions, e.g. isn't, aren't, hasn't, haven't, hadn't, don't, doesn't, didn't, won't, shan't, shouldn't, wouldn't, couldn't, needn't, mustn't, yeah, 'til.

Use of non-standard contractions: gonna, dunno, wanna, ain't, 'cos, gotta.

\section{References}

Antaki, Charles, Rebecca Barnes and Ivan Leudar (2005) "Self-disclosure as a situated interactional practice". British Journal of Social Psychology 44, 181-199.

Atkinson, J. Maxwell and Paul Drew (1979) Order in Court: The Organisation of Verbal Interaction in Judicial Settings. London: Macmillan [for the] Social Science Research Council.

Bargiela-Chiappini, Francesca and Catherine Nickerson (2001) "Partnership research: A response to Priscilla Rogers". Journal of Business Communication 38 (3), 248-251.

Bargiela-Chiappini, Francesca and Catherine Nickerson (2002) "Business discourse: Old debates, new horizons". IRAL - International Review of Applied Linguistics in Language Teaching 40 (4), 273-286.

Bhatia, Vijay K. (1993) Analysing Genre: Language Use in Professional Settings. London: Longman.

Bhatia, Vijay K. (2004) Worlds of Written Discourse. London: Continuum.

Drew, Paul and John Heritage (1992) Talk at Work: Interaction in Institutional Settings. Cambridge: Cambridge University Press.

Greatbatch, David and Robert Dingwall (1989) "Selective facilitation: Some preliminary observations on a strategy used by divorce mediators". Law \& Society Review 23 (4), 613-641.

Handford, Michael (2010) The Language of Business Meetings. Cambridge: Cambridge University Press.

Heath, Christian (1992) "The delivery and reception of diagnosis in the general practice consultations”. In: Drew, Paul and John Heritage (eds.) Talk at Work: Interaction in Institutional Settings. Cambridge: Cambridge University Press, 235-268. 
Heritage, John (1985) "Analyzing news interviews: aspects of the production of talk for an 'overhearing' audience”. In: van Dijk, Teun (ed.) Handbook of Discourse Analysis, Volume III. London: Academic Press, 95-119.

Heritage, John (1997) "Conversation Analysis and Institutional Talk: Analysing Data”. In: Silverman, David (ed.), Qualitative Research: Theory, Method and Practice. PUBLISHER, 161-182.

Heritage, John (2005) "Conversation Analysis and Institutional Talk". In: Fitch, Kristine L. and Robert E. Sanders (eds.) Handbook of Language and Social Interaction. London: Lawrence Earlbaum Associates, 103-149.

Heritage, John and Steven Clayman (2010) Talk in Action: Interactions, Identities, and Institutions. Chichester, U.K.; Malden, MA: Wiley-Blackwell.

Heritage, John and Rod Watson (1979) "Formulations as conversational objects". In: Psathas, George (ed.), Everyday Language: Studies in Ethnomethodology. New York: Irvington Publishers, $123-162$.

Lohrová, Helena (2012) Internal meetings: The process of decision-making in workplace discourse. Unpublished PhD Thesis. Birmingham: University of Birmingham.

Lohrová, Helena (2014) "CA as a methodology in investigating the language of decision-making". Studies in Applied Linguistics 2014 (1), 27-47.

Sarangi, Srikant and Celia Roberts (1999) (eds.) Talk, Work and Institutional Order: Discourse in Medical, Mediation and Management Settings. Berlin and New York: Mouton de Gruyter.

Scott, Marvin B. and Stanford M. Lyman (1968) “Accounts". American Sociological Review 33 (1), 46-62.

Sinclair, John M. and Malcolm Coulthard (1975) Towards an Analysis of Discourse: the English Used by Teachers and Pupils. London: Oxford University Press.

Helena Lohrová holds a PhD in Applied Linguistics from the University of Birmingham. She is currently lecturing in Linguistics at the Institute of English Studies, University of South Bohemia. Previously, she worked for a number of years at the University of Birmingham and the University of West Bohemia. In her thesis entitled Internal meetings: The process of decision-making in workplace discourse, she applied Conversation Analysis (CA) as a methodology for the investigation of how decisions are reached discursively in business meetings. Her present research interests are in the areas of spoken workplace and institutional discourse, and she is particularly interested in clarifying the communicative roles of selected discursive practices. As a teacher and trainer, she is active in applying the insights gained during the research to the development of teaching materials and business communication training in the workplace.

Address: Mgr. Helena Lohrová, Ph.D., Institute of English Studies, Faculty of Philosophy, University of South Bohemia, Branišovská 31a, 37005 České Budějovice, Czech Republic. [hlohrova@ ff.jcu.cz] 
